\title{
Patient's Voices on Nurse Competence. Are we there?
}

\section{Gill BK*}

The Open University of Hong Kong, Hong Kong

*Corresponding author: Baljit Kaur Gill, The Open University of Hong Kong, Hong Kong, Tel: (852) 31202639; Email: dr.baljitkaurgill@gmail.com

\section{Review Article}

Volume 3 Issue 1

Received Date: February 14, 2019

Published Date: February 25, 2019

\section{Abstract}

Nurse competence is discussed and assessed globally and the importance of nurse competence plays a significant role in providing quality healthcare to the patients and the development of professional values of nurses. According to the National League for Nursing (2008), the four main areas of nurse competence are professional values, communication and interpersonal skills, nursing practice and decision making and leadership, management and team working. Nevertheless, patients' view and voices play vital importance in determining the standard and criteria of nurse competence which should not be neglected as they are receiver and end-user of quality healthcare services. This paper evaluated the patient's perception on the main four areas of nurse competence. It also concluded that impact of the patient's view on nurse competence improve health condition, establish a therapeutic relationship between nurse and patient and lastly promote the development of professionalism. Nurse competences also improve and enhance the role of nurses' as a caregiver, communicator and health promoter.

Keywords: Nursing; Patients; Professional values; Knowledge

Abbreviations: NCS: Nurse Competence Scale; LACE: Licensure Accreditation Certification and Education; ECT: Electroconvulsive Therapy; SIDS: Sudden Infant Death Syndrome.

\section{Introduction}

Assessing competence has been repeatedly stated on different nursing agendas. The Nursing and Midwifery Council keeps emphasizing the significance of competence standards to nurses, in order to meet altering health care priorities and lifelong career development of nurses [1]. Nursing can be categorized into four main areas of professional nursing practice, namely professional values; communication and interpersonal skills; nursing practice and decision making; and leadership, management and team working [2]. However, health care structure has changed that patient involvement has become the prime issue in health services. Patient's view on competence of nurses, who may be the most intimate carers, will continuously gain more value within the whole nursing process.

This article aimed to provide a comprehensive review of the desired nursing qualities from the patient's perspective of nursing competence according to the four main areas of nurse competence (professional values, communication and interpersonal skills, nursing practice and decision making and leadership, management and team working). Then, it would provide discuss how the patients' view on nurse competence brought impact on nursing professionals and development of nurse-patient relationship. 


\section{Nursing \& Healthcare International Journal}

\section{Importance of Nurse Competence in a Global Context}

Patients from numerous nations have showed their viewpoints on nurse competence, indicating that importance was placed on nurses' actions. In Korea, there are various issues concerning patient safety in clinical practice [3-5]. Nurses are likely to gain confidence in addressing patient safety issues through accumulated clinical experiences. Patient safety involves the prevention, reduction and alleviation of unnecessary injury and harm. Patients in Korea rated nurses' safety competence as moderate and it has been investigated that demonstration of patient safety competence was higher among experienced nurses. This result can be interpreted in a similar manner to the finding that duration of clinical experiences was strongly related with a nurse's clinical experience years.

In Germany, patients expressed that social skill is an important criteria of nurse competence because creating a trustful care relationship is vitally important [6]. They indicated nurses' appropriate behavior and attitude, composure, making time for patients, and listening and having empathy are essential attributes in demonstrating nurse competencies. According to their opinions, these social skills convey a sense of commitment to them and play a major role in meeting their expectations, because nursing care is about being heard and seen from their perspective. Nurses must have the ability to develop and maintain good relationships with patients. Nurses allay their fears and uncertainty with confidence and hope. If patients are not clear and certain of what they will be facing in their hospitalization, then they will be more suspicious and anxious.

In an oncology ward of Norway, patients regarded knowledge about cancer and its treatment as basic in nursing and took for granted that nurses had this competence [7]. They explained that knowledge is crucial and it enables patients to feel safe and secure, and alleviates suffering by providing useful information. It alleviates suffering and insecurity during chemotherapy, and relieves side effects caused by the treatment and disease. They appreciated nurses who were experienced and could combine clinical and biologic knowledge with a human touch.

\section{Four Main Areas of Nurse Competence}

There are four main areas professional nurse practice, namely 1) professional values; 2) communication and interpersonal skills; 3) nursing practice and decision making; and lastly 4) leadership, management and team working [2].

\section{Professional Values}

According to National League for Nursing (2018), professional values of nursing refer to caring, integrity, diversity and excellence [8].

\section{Caring}

Caring is a fundamental part of the nursing profession, which characterizes nursing concern, consideration and commitment to the patients [9]. Patients view a 'caring nurse' as being altruistic, compassionate, and generous, who can make decisions based on patients' best interests. It can be demonstrated by being the patient-centered advocate that ensures patients being well-informed about their treatment plan, secure patient safety and provide patients with the best quality care. Caring can also boost altruism which helps unlock a nurse's compassion and empathy skills, allowing a more positive and healing environment for the patient [10]. A research cited patients' perception of a competent nurse that 'how would I feel in their shoes?' implying patients expect caring nurses to understand the feeling of being nursed in an empathetic way [11]

\section{Integrity}

Integrity is the respect of human dignity and moral wholeness of every person without conditions or limitations [12]. Patient views an integrity nurse as a guardian of their dignity, autonomy and social justice in which patients are respected and dignified [13], patients gain control in health care decisions [14] and patients are distributed with reasonable amount of health care resources and services through the nursing-patient relationships and interactions within the healthcare system [15]. Understanding and listening to patient's specific reasons for early discharge is a way of preserving dignity, regardless the feasibility of the requests. Besides, integrity is viewed as a quality that encompasses honesty and truthfulness [16]. The patient expects integrity in nurses to disclose them valid and true information regarding their health conditions while these private information should be kept confidential.

\section{Diversity}

Diversity is affirming the uniqueness and differences among persons, ideas, values, and ethnicities [8]. Patients' views on diversity of nursing as a culture of inclusive excellence that encompasses many identities influenced by the intersections of race, ethnicity, gender, sexual 


\section{Nursing \& Healthcare International Journal}

orientation, socioeconomic status, age, physical abilities, religious and political beliefs, or other ideologies. In view of this, patients expect competent nurses to facilitate their access to culturally and linguistically appropriate services; and safe and timely care, including preventive and specialist services [17]. Differences among patients affect nursing judgments and thus competent nurses must work to understand both themselves and patients' needs throughout the nursing processes.

\section{Excellence}

Excellence is co-creating and implementing transformative strategies with daring ingenuity [8]. Patients view the excellence of nursing as maintaining the best standard of nursing care despite challenges or pressures to lower the standard. Most patients recognize nurses are stressed under heavy workload, but being busy should not be the excuse of substandard care [11]. It reflects a commitment to continuous growth, improvement, and understanding in patient care, in which transformation is embraced while the status quo and mediocrity are not tolerated [18]. Nursing skills, interventions and evaluations are continuously reviewed. Research study are repeatedly carried out in different aspect so as the nursing practice are revised to achieve and maintain excellent performance in practice of patient care. The practice of essential skills clusters also supports the achievement of standards of competence and different standards for competence that apply to a specific field of nursing. This also results in developing and implementation of evidence-based practice. Nurses also maintain their competence through professional development in order to equip themselves with the most updated nursing care. In other words, ethical principles of beneficence and nonmaleficence are born so that acts to maximize patients' benefits are promoted while acts to cause harm to patients are minimized.

\section{Communication and Interpersonal Skills}

Communication is a mutual process of sending and receiving messages by using a mixture of interpersonal skills, including verbal and non-verbal [19], it is used to build rapport between nurses and patients. When it comes to communication in nursing, it involves not only the transmission of information, but also feelings, which should be recognized in a nurse-patient relationship [20]. We can easily foresee that effective communication with application of interpersonal skills between nurses and patients can build up a rapport and generate a mutual goal to promote patient health.

\section{Importance of an Effective Communication}

In the present society, patients are more likely to get information about their illness, treatment and the medical procedures and highly involved to make own health choices. Patients will tend to obtain more information in order to make a comprehensive decision. However, physicians may not provide adequate information to patients. Patients cannot have adequate information to support their decision. The patient will regard a competent nurse to provide reliable advices and information with consideration of their difficulties. Nurses have the responsibility to answer patients' concerns through their knowledge and experience, while acknowledge patient with important information about interventions.

Furthermore, nurse as a coordinator has to communicate between different medical professionals. Seyedeh Belin, et al. (2018), they found that improvement in communication skill of health providers is effective to cope with patients with uncontrolled blood pressure [21]. An effective communication played a vital role to promote well-being. If the patients could receive adequate information about benefits, risks and any adverse effects of medical interventions, they will feel comfortable and satisfied [22]. An effective communication allows nurses to deliver information for patients, better cooperate with patients and improve patient understanding on interventions so as to supervise nursing actions. A careful and precise communication can also minimize potential risks of many nursing procedures, preventing possible harm on patients. Therefore, communication is also an important constituent indicating nursing competence.

\section{Communication Enhance Interpersonal Skills}

Nurses communicate with patients with interpersonal skills to provide emotional support and avocation. Communication among nurses and patients can involve a positive talk, psychosocial counseling, psychosocial question asking, and emotionally focused talk [23]. A supportive communication can promote the sense of comfort of patients and allays their negative feelings. Communication is seen as an essential part of the quality nursing care and fundamentally affects patient satisfaction [24]. Good communication in interpersonal skills before treatment, including explanation and duration of procedures are believed to relieve negative feelings generated, such as fear and worries, and enable them to comply with the treatment.

Moreover, good discussion after treatment allows patients to evaluate the effectiveness of treatment, 
prevention of unfavorable complications, and above all, enhance emotional comfort. Moreover, through nursepatient communication, nurses can identify patients unspoken needs and provide suitable nursing care or treatment. Through communication, individuals are given chances to perceive themselves by expressing their feelings and memories to others consciously or unconsciously [24]. For instance, after establishing trust and rapport in nurse-patient relationship, patients will be willing to express their views. And hence nurses are able to complete an accurate and complete assessment for elderly with risk of depression and suicidal thought, and provide with follow-ups when required [25]. Generally speaking, a supportive communication can promote patients' well-being as many patients are worried about the unknown intervention.

\section{Nursing Practice and Decision Making}

Nursing practice and the decision making are based on nursing knowledge which could enhance a favorable nursing care on patients. The third component of nursing competence is nursing practice and decision making. Calmon (2006) stated, patients described a cornerstone of competent nursing practice was nursing knowledge [16]. Based on the different aspect of knowledge, nurses can make a patient-centered decision and practice to encounter the needs of patients. Patients would regard that nurse as a competence nurse if their needs are being well treated.

\section{Patient's View in Nursing Practice}

When patients were asked about nursing competence, technical skill usually was the first thing come to their mind [26]. Patients assumed proficient nursing skills to be implemented and it has been considered as in the realm of nurses [26]. Patient expected a competent nurse to be experienced and practice repeatedly, hence providing flexible, appropriate and consistent nursing care [26]. The experience can foster advanced nursing practice, facilitate nurses to implement skillful intervention and enhance nurse's confidence, as a result promoting patient positive experience [27]. Patients also consider that there are differences in technical skill levels among nurses which affect the quality of care received [26-28]. For instance, patient described having noticeable differences in pain level of receiving suppository from different nurses and said "It is all about skills" [26].

Besides general clinical skills, patients also assess nurses' competence in providing flexible and adaptable care to alleviate their discomfort. For example, a postpartum mother had distinct experiences from two nurses [26]. She was taught by a nurse about wearing postpartum girdle, but she felt pain against her wound. Another nurse taught her to apply a supporting pad near her wound before wearing the postpartum girdle, then she felt much better [26]. To be a competent nurse, it is not only about being skillful but also considerable when providing care. Patient judge, nurse competence based on the quality of nursing care provided.

\section{Nursing Practice through Hospital Guidelines, Patient Experience and Personal Knowledge}

Hospitals provide various guidelines and protocols to conduct nursing practice based on research and clinical evidence. The application of evidence-based practice is widely adopted in health care settings. Theoretically, following guidelines can maximize health outcomes of nursing interventions. Therefore, nursing practice should align with guidelines as well as the knowledge and expertise of the individual [29]. However, patients want not only the provision of standard nursing practice, but also take their emotional needs into consideration during nursing interventions- 'A competent nurse should allow themselves to be touched by patients' stories, see the patient's unspoken wishes to be listened to and have the will to meet patients' expressed needs in their present situation' [30]. Furthermore, evidence indicated that increasing nursing knowledge enables nurses to be more confident to handle patients' discomfort, concerns or emergency situations, in order to enhance patients' health and wellbeing. In a study, researchers implemented a training program for neonatal nurses and there was a significant improvement on nurse competence and quality of care, including crucial patient outcome such as mortality [27]. Patients expect that nursing practice could be conducted with respect, with the clinical guidelines and nursing knowledge involved.

\section{Use Knowledge to Make Decisions}

A competent nurse can make use of the theoretical knowledge to guide their decision-making process in order to improve patients' satisfaction during their hospitalization. Nurses acquired theoretical knowledge from schools, books or journals which helps to enhance their knowledge and cognitive development. Knowledge provides quantifiable and measurable information about the practice [31]. When handling problems and concerns from patients, using theoretical knowledge can guide nurses to make evidence-based decisions to provide comprehensive care for patients. Nurse competence is also addressed in providing nursing care to their patients. In the study of the application of theory model into 


\section{Nursing \& Healthcare International Journal}

practice [32], researchers discovered that combining the use of Bandura's social cognitive theory and Orem's selfcare theory in the care of palliative patients enhanced nursing competence. The life-limited patients experienced a feeling of respect and satisfaction through strengthening their self-care ability. Applied nursing theory is an example to show that knowledge contributes to decision making and result in better outcomes in patients. In daily practice, nurses face a lot of challenges, such as options and the dilemma during nursing care. From the patient's view, a competent nurse should be able to make patientcentered decisions with recognition of actual needs by using broad knowledge and evidence. The assessment of a competent nurse can also be evaluated by Nurse Competence Scale (NCS).

Decision-making and nursing practice are other components of nursing competence. Patient's well-being and health are directly related to the decision and practice made by the nurse. In the view of patients, they are willing to receive patient-centered care from a nurse. A competent nurse should make the decision based on various evidence and information and provide comprehensive nursing intervention to deal with the needs of patients.

\section{Leadership, Management and Team Working}

Nurse leadership refers to the actions of nurses in charge of the situation, and a teamwork relationship exists when involved professionals interact and manage mutual decisions which based on knowledge and expertise, with a harmonious manner [6]. Among the four areas of nursing competence, leadership and teamwork are the least discussed area by patients. Patients mainly interpret nursing competence based on the quality of care they received. While leadership and teamwork are not directly related to the quality of care, patients' opinions represent differently.

\section{Polarized Viewpoints on Nursing Leadership}

Nurse leadership usually refers to the actions of the nurses' in-charge of the situation. It is often affiliated with management, coaching and mentoring [33]. With rapid changes in medical and nursing technologies, nurse leaders are required to guide this profession to sustain its advancement [34]. A nurse with leadership competence should demonstrate the following characteristics: ensure adequate clinical resources, delegate work appropriately according to colleagues' abilities, be concerned about the career development of junior colleagues, and ensure high quality care being delivered without interference of the management system (e.g. poor care continuity due to shifting) [35].

These components appear to be irrelevant to patients themselves; however, nursing leadership competence plays an important role in a variety of patient outcomes, especially on patient satisfaction and safety. Patients' perceptions of nursing teamwork have been polarized into compulsory and unnecessary. Some research highlighted the explanation that nurses with leadership competence facilitate patient care by appropriate use of resources, staffing levels and care procedures [36], therefore there is a positive satisfaction level from a patient's view. Another research mentioned that patients even expect every registered nurse should be the leader of the nursing team because they are believed to be specialized in different areas [37]. For examples, newlygraduated nurses who constantly perform bedside care are more familiar with their patients and can be the leader to advocate patient education. Managers and experienced nurses are capable of creating a favorable ward culture to encourage junior staff and students to feel esteemed and perform at their best. Some patients yet do not consider nurses as competent in the leading role; because their foremost value of leadership is decisionmaking power a nurse can provide [38].

\section{Nursing Teamwork from Patient's Observations}

Teamwork relationship exists when involved professionals interact and manage mutual decisions which based on knowledge and expertise, with a harmonious manner [6]. In a recent study related to patient safety, nurses' teamwork with other health care practitioners was ranked the lowest among other dimensions. Other research also stated that patients view teamwork competence among nurses is rather weak when compared with practical skills and professional knowledge [39]. It indicates the weakness of the current healthcare system and the nature of nursing which is the occupation-specific specialization. A holistic patient care is a complex process that requires multidisciplinary collaboration between healthcare professionals, so effective teamwork is mandatory to ensure quality of care and patient safety. However, in some patients' comments about nursing teamwork behavior, inter-professional dynamics and team interactions in their own rooms are always the main focus, instead of nursing roles and processes within the team [40]. Patients rarely put importance on the nursing role in the healthcare team, because they usually interpret team work competence through direct observations. Thus, team image and 


\section{Nursing \& Healthcare International Journal}

interactions which are more easily observed will be the key aspects in the patient's view. Another research revealed some patients do not aware of the responsibilities of nurses to make clinical decisions in a team, which should be held by physicians [38].

\section{Reflection of Patients' View on Nurse Competence}

Patient's view on nursing competence has exerted influence on different healthcare perspectives, namely 1) improvement in health condition, 2) establishment of a therapeutic relationship and lastly promotion of professionalism.

\section{Improvement in Health Condition}

Supportive and helpful attitude helps the promotion of health conduction. Edvardsson, et al. (2017) revealed that caring and person-centeredness are proved to be highly associated with nursing care quality [41]. They can be categorized as professional value, which is one of the compartments of nursing competence. As revealed, professional value such as 'being supportive' and fulfilling both 'the stated and unstated needs', are shown to be substantially correlated to high quality of nursing care. Quality nursing care is conducive to positive patient experience and positive patient experiences is contributory to the reduction of utilization of health care services, decreased annual medical charges, and lower the mortality rate of certain disease [42].

\section{Establishment of a Therapeutic Relationship}

Communication is important in constructing a reliable nurse-patient relationship. In accordance to Kieft, Brouwer, et al. (2014), it is shown that social skills are fundamental nursing competencies, such as appropriate behavior and attitude, composure and listening, of which can alleviate patients' worry and uncertainty, and then fosters trust and appropriate hope in them and it demonstrate a sense of dedication to patient and help fulfil patient needs and expectation [6]. Moreover, nurses are deemed to be more reachable than other healthcare professionals and hence are expected to be a bridge between patients and other professionals [6]. As a result, patients may tend to rely on and seek help from nurses, and express their thoughts and worries to nurses. Since patients have a tendency to open up to nurses, it also helps nurses to cope with patients' problems and promote the establishment of the trusty therapeutic relationship.

\section{Promotion of Professionalism}

Furthermore, Kieft, et al. (2014) also stated that knowledge and technical skills are inferred by patients that should be present, which in return make nurses continuously strive for knowledge and learn the latest nursing care and information [6]. Nurses are expected to provide effective and harmless care, keep in touch and provide with the most recent intervention [6]. Moreover, nurses are the closest healthcare providers to patients that patients have to place trust in nurses [43]. There is trust and belief in nurse-patient relationships. As a result, nurses will and should continually acquire different nursing knowledge and align with the agreed nursing policy, which will finally lead to the development of evidence-based nursing practice and hence promote professionalism.

\section{Competence Provides a Clearer Role for Nurses}

There are both challenges and opportunities when it comes to sharpening nursing competence in both clinical and community settings. In fact, nursing competence is essential to promoting patient safety, developing a therapeutic relationship and enhancing health promotion in a global perspective. Competence helps to shape the nurses' role as a caregiver, communicator and health promoter.

\section{Nurses as a Caregiver}

In view of patient safety issues, a competent nurse should bear the role of caregiver, who has traditionally included in primary health care activities that assist the client physically, psychologically and preserving the client's dignity nowadays [44]. However, these health care services encompass the physical, psychosocial, developmental, cultural and spiritual levels, which impose challenges on competent nurses to comply with professional values in every delicate part of nursing processes to ensure high quality care and patient safety. Nurses should adhere to professional values to be caring and cautious so that they can predict and prevent potential dangers that harm patient safety. Therefore, nurse practitioners should be held accountable for their contributions to high-valued primary care. Reports to disclose health care provider performance information to the public may be required. For example, the Agency for Healthcare Research and Quality's Health Care Quality Report Card Compendium has inventoried more than 200 


\section{Nursing \& Healthcare International Journal}

sources of comparative information on health care providers, including health plans, hospitals, medical groups, and individual nurse practitioners [45].

As the performance of the whole multidisciplinary team is measured and disclosed, comparable results of nurse practitioners' performance can be publicly available. It stimulates the quality improvement of nursing care and facilitates patients' selection of competent health caregivers that provide them confidence in protecting patient safety and patient-centered care [46]. Besides, a competent nurse should provide standards of care which identify expected levels of care are delivered to patients receiving disease prevention and management [47].

Standards can ensure that care delivery is of a consistently high level and unwarranted variation is reduced. Therefore, substantial efforts should be made to standardize nursing acts. For example, the Consensus Model for Advanced Practice Registered Nurse Regulation can be applied in caring for the current and future health needs of patients [48]. The licensure, accreditation, certification and education (LACE) of advanced practice registered nurse need to be effectively aligned in order to ensure patient safety while expanding patient access to quality health care [49]. Competent nurses should receive licensure from authority to practice; accredited by the recognized agency of educational degree or certification programs in nursing; formal certification of knowledge, skills, and experience standards identified by the profession department as well as education of advanced practice registered nurse in graduate degree-granting or postgraduate certificate programs. Take wound dressing as an illustration, nurses should apply the standard aseptic technique in order to avoid wound infection [50]. These standard care procedures should be refined continuously and then incorporated into LACE worldwide, which enhance the competence of all nurse practitioners in respect of promoting patient safety.

\section{Nurses as a Communicator}

In view of therapeutic relationship facilitation, a competent nurse should bear the role of communicator to understand various patients in the community. In the role of communicator, nurses should identify clients' problems and then communicate verbally or in writing to other members in the healthcare team. However, miscommunication can result in medical disputes that lead to detrimental relationships between nurses and patients [51]. Even worse, miscommunication may cause medical errors, leading to permanent harms or death of patients. According to a 2013 study published in the
Journal of Patient Safety, 440,000 patients die from preventable medical errors, representing the third leading cause of death in the US on the list from the Centers for Disease Control and Prevention [52]. Therefore, the quality of nursing communication is an important factor in nursing care.

In order to facilitate nurse-client relationship and the therapeutic process, Peplau's Interpersonal Relations Theory can be applied in nursing to help explain and guide interactions between nurses and patients, as well as nurses and other healthcare professionals [53]. Peplau's interpersonal relations theory defines four stages of relationship for the achievement of a common goal, including orientation, identification, and exploitation and resolution phases. Take a case of major depressive disorder as an example, the nurse during orientation engages the patient in electroconvulsive therapy (ECT) and answer patients' inquiries and receive information regarding possible side effects like confusion, headache and nausea after ECT [54].

A competent nurse should demonstrate active listening to the patient's concerns [55]. This stage helps the patient develop trust towards the nurse and the healthcare system. The patient and nurse in the identification phase begin to work together. These interactions provide the basis for understanding, trust and acceptance as the patient becomes an active participant in the treatment (ECT). In exploitation phase, the patient takes advantage of all services offered, exploiting the nurse-patient relationship to address treatment goal of reducing depressive symptoms. As a result of effective communication, the patient's depressive symptoms are relieved in the resolution phase and the therapeutic relationship is successful [56].

Besides, a competent nurse should have good observation skills to assess patients' communication needs in respect to their age and developmental status, and modify care according to the patient's age-related needs [57]. For example, infants who have soft and fragile skin, are more susceptible to skin dehydration and infections [58]. Yet, they can only communicate and respond to nurses with behavioral cues like crying when they are in pain, uncomfortable or hungry. Therefore, a competent nurse should be sensitive to these subtle cues to meet infants' needs and prevent them from permanent harms like starvation and dehydration.

For cultural competence, competent nurses should sharpen their competence in language proficiency and cultural understandings so that they can communicate 


\section{Nursing \& Healthcare International Journal}

with patients with diverse cultural and religious backgrounds [59]. Take Jehovah's Witnesses blood transfusion case as an illustration, given that Jehovah's Witnesses have refused blood transfusions since a 1945 church decision [60]. These patients will die as they refuse blood transfusions. Thus, blood substitutes can be introduced by nurses to these patients or their significant others. Discussion on the combination therapy with erythropoietin and PolyHeme in the case of a critically ill Jehovah's Witness who needs blood transfusion to prevent death should be carried out [61].

Language proficiency is required to facilitate these patients' timely access to emergency health care services with language assistance services available (i.e. preferred languages in both verbally and written forms). Meanwhile, it increases patients' understanding about medical treatments, and thus minimizes medical errors due to miscommunication between nurses and patients from different backgrounds and countries.

\section{Nurses as a Health Promoter}

In view of health promotion, a competent nurse should take a crucial role in health promotion, who acts to promote patients' well beings and educate patients' information regarding health issues [62]. Nurses should implement strategies for health promotion that strives to reduce negative health outcomes associated with health determinants by increasing knowledge and selfmanagement through health education [63]. Therefore, nurses can apply the Health Promotion Model to promote health, which defines health as a positive dynamic state not merely the absence of disease, but an increasing patient's level of well beings [64]. There are three areas in the model to be followed. A case of diabetic foot ulcer can be an example. First, it is the individual characteristics and experiences of a diabetic patient who suffers pain from the foot ulcer caused by diabetes [65]. Second, it is the behavior-specific cognitions and significant motivational changes, when the diabetic patient is educated by the nurse about blood sugar testing and diabetic dietary control during wound dressing. Third, it is the behavioral outcome that results in improved health, enhanced functional ability and better quality of life when the patient initiates diabetic control advised by the nurse. Competent nurses can perform educational interventions in every interaction with a patient to promote patient health [66].

Besides, it is suggested that effective health promotion practice requires competent nurses to adopt a proactive stance and act as an advocate. Thus, nurses should adopt an affirmative and the egalitarian attitude towards patients as well as maintain the desire to promote their health and well-being [67].

However, because of the broad field of health promotion, more research is needed to examine the role of health promotion in nursing [68]. Competent nurses should carry out clinical research that is vital for finding new treatments and improving patient care. Take Sudden Infant Death Syndrome (SIDS) as an example, after years of nursing research, it was discovered that sleeping babies on their bellies rather than their backs could significantly reduce the mortality rate [69]. Nurses can develop new policies or procedures in the database shared by all hospitals. Thus, a broader field of health promotion can be narrowed by conducting nursing research from time to time. And the findings of new treatments can be widely spread to promote health in both clinical and community settings.

\section{Conclusion}

Acknowledging that patients are also concerned about and have their own views on nursing competence, the focus and perspective of competence should be no longer placed only on healthcare professionals. Nursing competence is the combination of professional values, communication, practice and decision-making proficiency, and leadership and teamwork capability. With the presence of faith of patients in nursing competence, patient's view on the above domains will be beneficial to not only therapeutic relationships and improved health outcomes, but also promotion of nursing professionalism. If the patient's view induces positive influences on healthcare, nursing roles of being caregiver, communicator and health promoter are suggested so as to sharpen the edge of competence in both clinical and community settings.

\section{References}

1. National Nursing Research Unit (2009) Nursing competence: what are we assessing and how should it be measured? King's College, London.

2. Nursing and Midwifery Council (2015) The Code: Professional standards of practice and behaviour for nurses and midwives.

3. Jang H, Lee NJ (2017) Patient safety competency and educational needs of nursing educators in South Korea. PLoS ONE 12(9): e0183536. 


\section{Nursing \& Healthcare International Journal}

4. Hwang JI (2015) What are hospital nurses' strengths and weaknesses in patient safety competence? Findings from three Korean hospitals. International Journal for Quality in Health Care 27(3): 232-238.

5. Hwang JI, Yoon TY, Jin HJ, Park Y, Park JY, et al. (2016) Patient safety competence for final-year health professional students: Perceptions of effectiveness of an interprofessional education course. Journal of Interprofessional Care 30(6): 732-738.

6. Kieft RA, de Brouwer BB, Francke AL, Delnoij DM (2014) How nurses and their work environment affect patient experiences of the quality of care: a qualitative study. BMC Health Services Research 14: 249.

7. Utne I, Smastuen MC, Nyblin U (2018) Pain Knowledge and Attitudes Among Nurses in Cancer Care in Norway. J Cancer Educ.

8. National League for Nursing (2018) The Voice of Nursing Education. Washington, DC: The United States.

9. Shaw HK, Degazon C (2008) Integrating the core professional values of nursing: A profession, not just a career. J Cult Divers 15(1): 44-50.

10. Watson J (2008) Nursing: The philosophy and science of caring. Boulder, CO: University Press of Colorado.

11. Bramley L, Matiti M (2014) How does it really feel to be in my shoes? Patients' experiences of compassion within nursing care and their perceptions of developing compassionate nurses. Journal of Clinical Nursing 23(19-20): 2790-2799.

12. Edgar A, Pattison S (2011) Integrity and the Moral Complexity of Professional Practice. Nursing Philosophy 12(2): 94-106.

13. Jacobson N (2007) Dignity and health: A review. Soc Sci Med 64(2): 292-302.

14. O’Neill O (2002) Autonomy and trust in bioethics. Journal of the Royal Society of Medicine 95(8): 423424.

15. Boudain DM (2005) Social justice as a framework for professional nursing. Journal of Nursing Education 44(9): 404-408.

16. Calman L (2006) Patients' views of nurses' competence. Nurse Educ Today 26(8): 719-725.
17. Mead GE, Morley W, Campbell P, Greig CA, McMurdo $\mathrm{M}$, et al. (2008) Exercise for depression. Cochrane Database Syst Rev (4): CD004366.

18. Jasovsky DA, Grant VA, Lang M, Devereux BF, Altier $\mathrm{ME}$, et al. (2010) How do you define nursing excellence? Nursing management 41(10): 19-24.

19. Arnold E, Boggs K (2016) Interpersonal relationships: professional communication skills for nurses $7^{\text {th }}$ (edn), St. Louis, Missouri: Elsevier.

20. Sheppard M (1993) Client satisfaction, extended intervention and interpersonal skills in community mental health. J Adv Nurs 18(2): 246-259.

21. Tavakoly Sany SB, Peyman N, Behzhad F, Esmaeily H, Taghipoor A, et al. (2018) Health providers' communication skills training affects hypertension outcomes. Medical Teacher 40(2): 154-164.

22. Puro H, Pakarinen P, Korttila K, Tallgren M (2011) Verbal information about anesthesia before scheduled surgery - contents and patient satisfaction. Patient Educ Couns 90(3): 367-371.

23. Roter DL, Hall JA (2004) Physician Gender and Patient-Centered Communication: A Critical Review of Empirical Research. Annual Review of Public Health 25(1): 497-520.

24. Fleischer S, Berg A, Zimmermann M, Wüste $K$, Behrens J (2009) Nurse-patient interaction and communication: A systematic literature review. Journal of Public Health 17(5): 339-353.

25. Plawecki LH, Amrhein DW (2010) Someone to Talk To: The Nurse and the Depressed or Suicidal Older Patient. J Gerontol Nurs 36(5): 15-18.

26. Cy Chan Z, Wong KS, Lam WM, Wong KY, Kwok YC (2014) An exploration of postpartum women's perspective on desired obstetric nursing qualities. Journal of clinical nursing 23(1-2): 103-112.

27. Guiles S, Lemons J, Trautman M, Bucher S, Songok J, et al. (2016) The Implementation of a Neonatal Nurse Training Program at the Riley Mother Baby Hospital of Kenya. Newborn and Infant Nursing Reviews 16(4): 184-189.

28. Stahlke S, Rawson K, Pituskin E (2017) Patient Perspectives on Nurse Practitioner Care in Oncology in Canada. J Nurs Scholarsh 49(5): 487-494. 
29. Catherine MK, Becky P (2017) How Correctional Agencies Can Support Professional Nursing Practice. Correctional Health Care Report 18(3): 33-48.

30. Lindwall L, Boussaid L, Kulzer S, Wigerblad A (2012) Patient dignity in psychiatric nursing practice. Journal Of Psychiatric And Mental Health Nursing, 19(7): 569567.

31. Mantzoukas S, Jasper M (2008) Types of nursing knowledge used to guide care of hospitalized patients. Journal of Advanced Nursing 62(3): 318-326.

32. Desbiens JF, Gagnon J, Fillion L (2012) Development of a shared theory in palliative care to enhance nursing competence. Journal of Advanced Nursing 68(9): 2113-2124.

33. Stanley D, Sherratt A (2010) Lamp light on leadership: clinical leadership and florence nightingale. J Nurs Manag 18(2): 115-121.

34. Grossman S, Valiga T (2012) The new leadership challenge - Creating the future of nursing $4^{\text {th }}($ edn $)$, Philadelphia, FA Davis Company, United States of America.

35. Stuart CC (2013) Mentoring, Learning and Assessment in Clinical Practice, A Guide for Nurses, Midwives and Other Health Professionals: Mentoring, Learning and Assessment in Clinical Practice $3^{\text {rd }}$ (Edn.), Netherlands, Elsevier Health Sciences, United States of America.

36. Havig AK, Skogstad A, Kjekshus LE, Romoren TI (2011) Leadership, staffing and quality of care in nursing homes. BMC Health Services Research 11: 327.

37. Larsson IE, Sahlsten MJ, Segesten K, Plos KA (2011) Patients' perceptions of barriers for participation in nursing care. Scandinavian Journal of Caring Sciences 25(3): 575-582.

38. Pullon S, McKinlay E, Stubbe M, Todd L, Badenhorst C (2011) Patients' and health professionals' perceptions of teamwork in primary care. Journal of Primary Health Care 3(2): 128-135.

39. Ginsburg LR, Tregunno D, Norton PG (2013) Selfreported patient safety competence among new graduates in medicine, nursing and pharmacy. BMJ Qual Saf 22(2): 147-154.
40. Henry BW, McCarthy DM, Nannicelli AP, Seivert NP, Vozenilek JA (2016) Patients' views of teamwork in the emergency department offer insights about team performance. Health Expect 19(3): 702-715.

41. Edvardsson D, Watt E, Pearce F (2017) Patient experiences of caring and person-centredness are associated with perceived nursing care quality. J Adv Nurs 73(1): 217-227.

42. Meterko M, Wright S, Lin H, Lowy E, Cleary PD (2010) Mortality among patients with acute myocardial infarction: the influences of patient centered care and evidence-based medicine. Health Services Research 45: 1188-1204.

43. Dinc L, Gastmans C (2013) Trust in nurse-patient relationships: a literature review. Nursing Ethics 20(5): 501-516.

44. Van Lerberghe $W$ (2008) The world health report 2008: primary health care: now more than ever. World Health Organization.

45. Linzer M, Manwell LB, Williams ES, Bobula JA, Brown RL (2009) Working conditions in primary care: physician reactions and care quality. Ann Intern Med 151(1): 28-36.

46. Ignatavicius DD, Workman ML (2015) MedicalSurgical Nursing-E-Book: Patient-Centered Collaborative Care. Netherlands, Elsevier Health Sciences, United States of America.

47. O'Connell J, Gardner G, Coyer F (2014) Beyond competencies: using a capability framework in developing practice standards for advanced practice nursing. J Adv Nurs 70(12): 2728-2735.

48. Stanley JM, Werner KE, Apple K (2009) Positioning advanced practice registered nurses for health care reform: Consensus on APRN regulation. J Prof Nurs 25(6): 340-348.

49. Avery MD, Germano E, Camune B (2010) Midwifery practice and nursing regulation: licensure, accreditation, certification, and education. Journal of Midwifery \& Women's Health 55(5): 411-414.

50. Abdelrahman T, Newton H (2011) Wound dressings: principles and practice. Surgery-Oxford 29(10): 491495. 


\section{Nursing \& Healthcare International Journal}

51. Aoki N, Uda K, Ohta, S, Kiuchi T, Fukui T (2008) Impact of miscommunication in medical dispute cases in Japan. International Journal for Quality in Health Care 20(5): 358-362.

52. James JT (2013) A new, evidence-based estimate of patient harms associated with hospital care. Journal of patient safety 9 (3): 122-128.

53. Delaney KR, Shattell M, Johnson ME (2017) Capturing the Interpersonal Process of Psychiatric Nurses: A Model for Engagement. Archives of psychiatric nursing 31(6): 634-640.

54. Cook V (2018) A Shocking Solution: Electroconvulsive Therapy and its Effects on Depression and Other Mental Illnesses. BU Well 3: 10.

55. Bramhall E (2014) Effective communication skills in nursing practice. Nursing Standard 29(14): 53-59.

56. Mohn C, Rund BR (2016) Significantly improved neurocognitive function in major depressive disorders 6 weeks after ECT. Journal of affective disorders 202: 10-15.

57. Morton PG, Fontaine D, Hudak CM, Gallo BM (2017) Critical care nursing: a holistic approach. Lippincott Williams \& Wilkins, pp: 1056.

58. Ness MJ, Davis DM, Carey WA (2013) Neonatal skin care: a concise review. International journal of dermatology 52(1): 14-22.

59. Hull M (2016) Medical language proficiency: a discussion of interprofessional language competencies and potential for patient risk. International journal of nursing studies 54: 158-172.

60. Marco R, Tommaso BF, Gianluca Z, Vanni A, Antonio C (2016) Perioperative Management of Patients
Refusing Blood Products. Int J Anesthetic Anesthesiol 3(4): 053.

61. Campbell YN, Machan MD, Fisher MD (2016) The Jehovah's Witness Population: Considerations for Preoperative Optimization of Hemoglobin. AANA journal 84(3): 173-178.

62. Matthews JH (2012) Role of professional organizations in advocating for the nursing profession. Online Journal Issues Nursing 17(3): 3.

63. Eldredge LKB, Markham CM, Ruiter RA, Kok G, Parcel GS (2016) Planning health promotion programs: an intervention mapping approach. John Wiley \& Sons.

64. Alligood MR (2017) Nursing Theorists and Their Work-E-Book. Netherlands, Elsevier Health Sciences, United States of America.

65. Yazdanpanah L, Nasiri M, Adarvishi S (2015) Literature review on the management of diabetic foot ulcer. World journal of diabetes 6(1): 37-53.

66. Bastable SB (2016) Essentials of patient education. Jones \& Bartlett Learning.

67. Potter PA, Perry AG, Stockert P, Hall A (2016) Fundamentals of Nursing-E-Book. Netherlands, United States of America: Elsevier Health Sciences.

68. Parahoo K (2014) Nursing research: principles, process and issues. Palgrave Macmillan.

69. Barsman SG, Dowling DA, Damato EG, Czeck P (2015) Neonatal nurses' beliefs, knowledge, and practices in relation to sudden infant death syndrome riskreduction recommendations. Adv Neonatal Care 15(3): 209-219. 